\title{
Test yourself question: multiple firm soft tissue masses
}

\section{Anika Choraria $^{1}$ (D) Asif Saifuddin ${ }^{1}$}

Received: 3 February 2021 / Revised: 15 March 2021 / Accepted: 16 March 2021 / Published online: 29 March 2021

(C) ISS 2021

\section{Question:}

An 80-year-old female patient presented with a 3-month history of firm swellings in the left groin, right hip and left shoulder. Apart from a previous history of breast cancer, treated several years prior with chemoradiotherapy and hormone treatment, she was otherwise fit and healthy. (Figs. 1, 2, 3, 4)

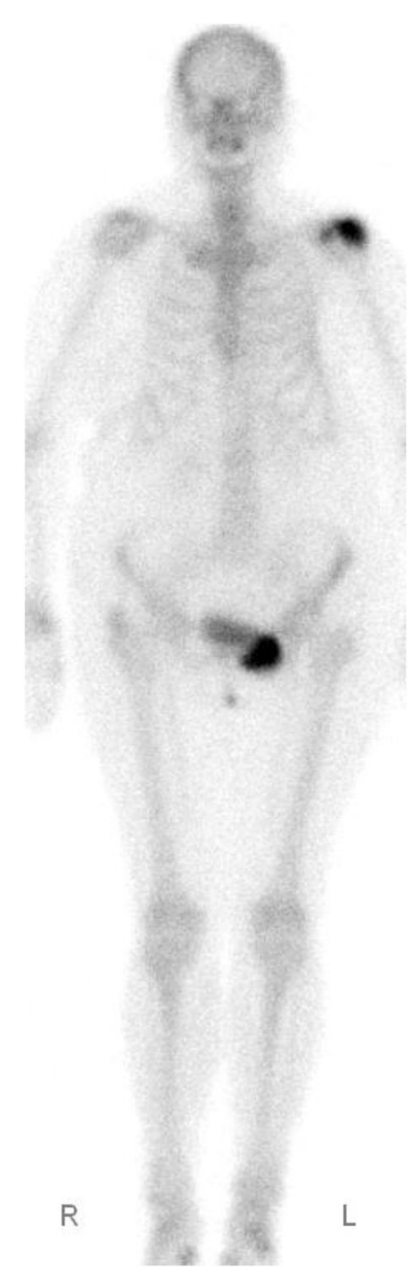

Fig. 1 Whole body bone scintigraphy using radiotracer ${ }^{99 \mathrm{~m}} \mathrm{Tc}-\mathrm{MDP}$

The diagnosis can be found at doi: https://doi.org/10.1007/s00256-02103762-3

Anika Choraria

choraria.anika@gmail.com

1 Department of Radiology, Royal National Orthopaedic Hospital, Brockley Hill, Stanmore, Middlesex HA7 4LP, UK 

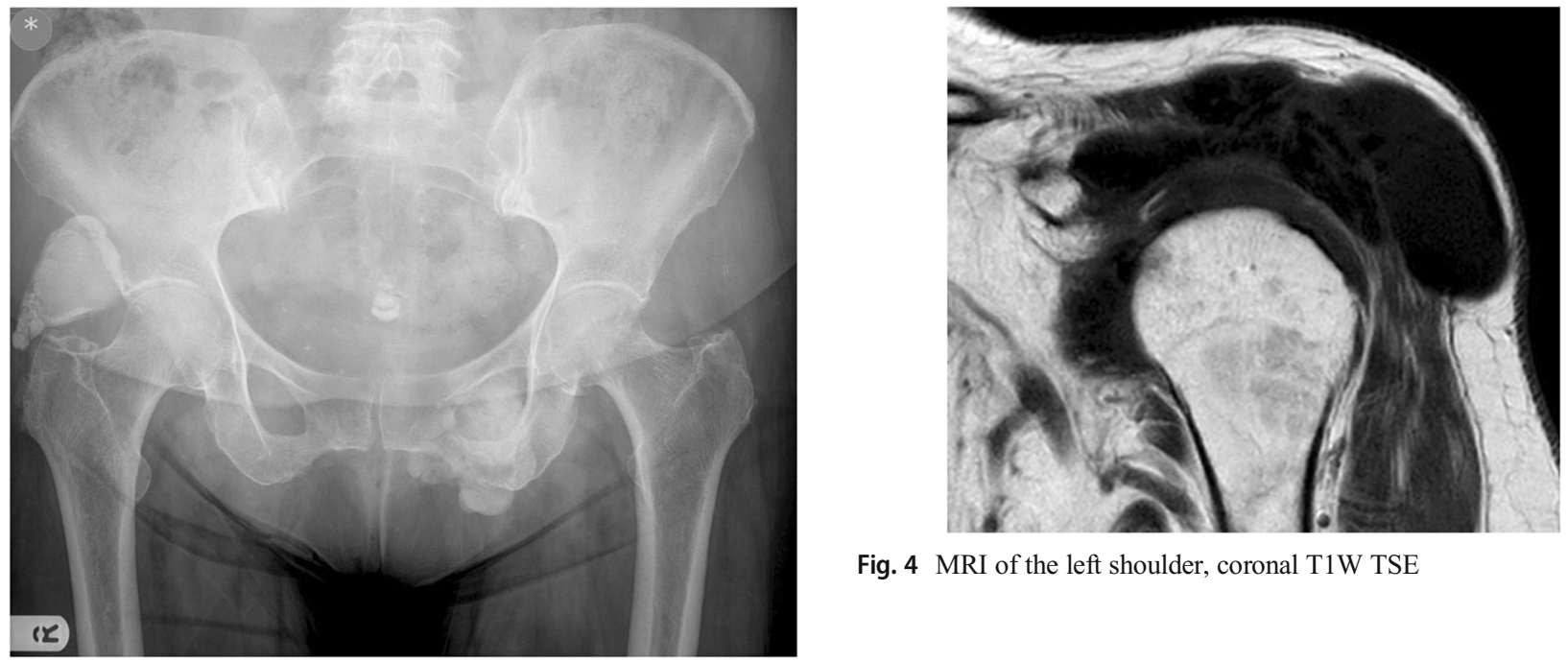

Fig. 4 MRI of the left shoulder, coronal T1W TSE

Fig. 2 AP radiograph of the pelvis
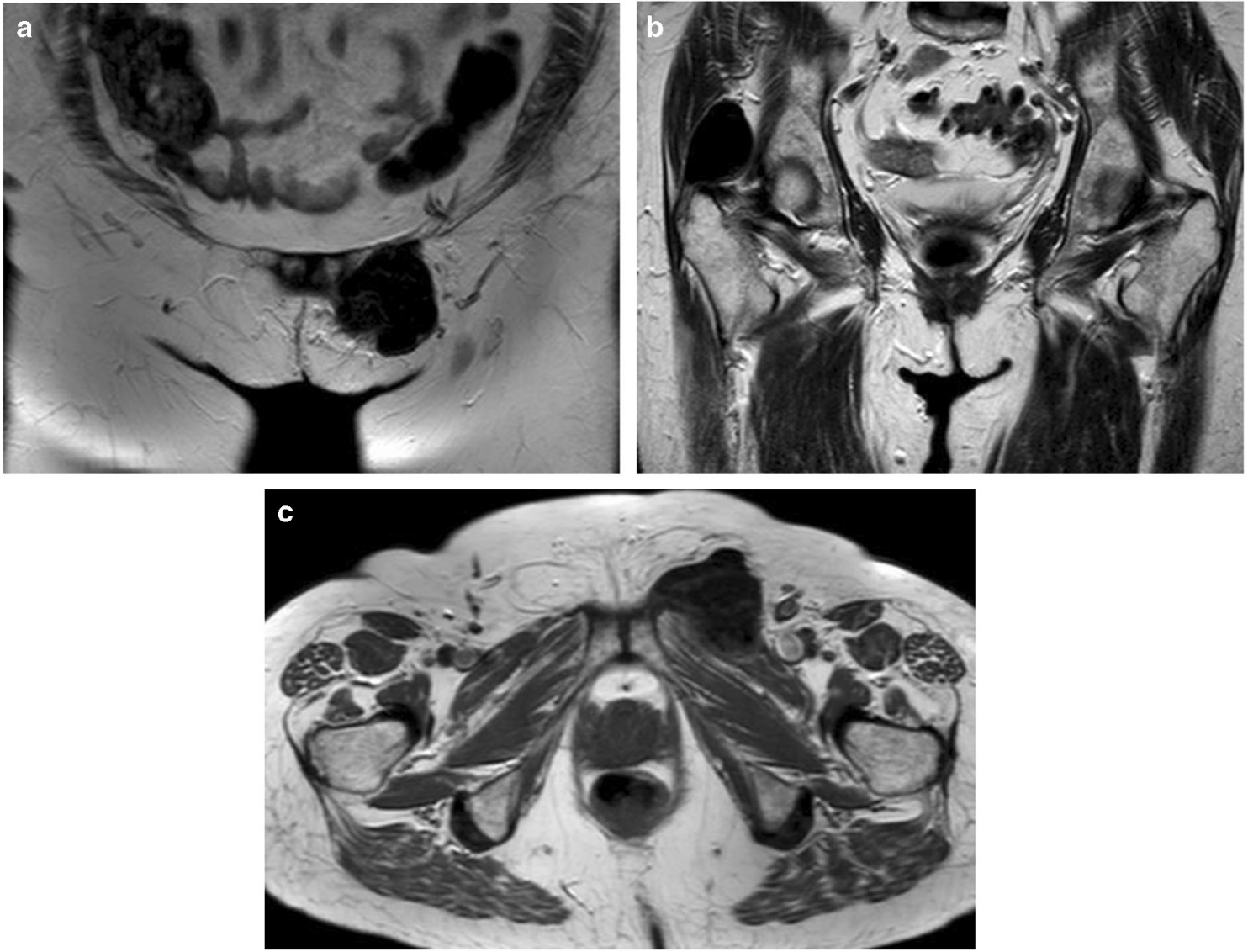

Fig. 3 MRI of the pelvis. a \& b Coronal T2W TSE images. c Axial T1W TSE

\section{Declarations}

Conflict of interest The authors declare that they have no conflict of interest.
Publisher's note Springer Nature remains neutral with regard to jurisdictional claims in published maps and institutional affiliations. 